\title{
METAFORE ISTINE U SRPSKOM JEZIKU ${ }^{1}$
}

\begin{abstract}
SAŽETAK
Predmet istraživanja jeste ispitivanje konceptualizacije apstraktnog pojma leksikalizovanog kao istina i utvrđivanje pojmovnih metafora kao mehanizama mišljenja. Na temelju postulata kognitivne lingvistike istražuju se osnovni izvorni domeni u kojima se konceptualizuje istina kao apstraktni pojam (entitet, biljka, životinja, osoba i sl.). Istraživanje se obavlja na Elekstronskom korpusu srpskog jezika (SrpKorp), iz kojeg će se ekscerpirati trista različitih primera koji sadrže datu leksemu (posmatraće se minimalni kontekstualni spojevi apstraktne imenice istina sa predikatima fizičke radnje, deskriptivnim pridevima i konkretnim imenicama) pri čemu će se posmatrati i funkcionalnostilska pripadnost izdvojenih primera. Izvršiće se statistička analiza, koja podrazumeva uvid u frekvenciju izvornih domena. Ukazaće se na elemente u konceptualizaciji značenja datog pojma koji otkrivaju osobenosti duha i kulture nosilaca srpskog jezika. Istraživanje počiva na postulatima konceptualne metode, jednog od krucijalnih alata za ispitivanje značenja $u$ kognitivnoj lingvistici.
\end{abstract}

KLJUČNE REČI: konceptualizacija, pojmovna metafora, izvorni i ciljni domen, istina.

\section{Uvod}

Predmet ovog istraživanja je ispitivanje konceptualizacije apstraktnog pojma leksikalizovanog kao istina i utvrđivanje pojmovnih metafora kao mehanizama mišljenja pomoću kojih se razumeva i organizuje stvarnost i koje se odražavaju u

${ }^{1}$ Istraživanje predstavlja proširenu verziju seminarskog rada iz nastavnog predmeta Leksička semantika, a rađeno je pod mentorstvom prof. dr Jasmine Dražić. Deo istraživanja prezentovan je na studentskoj konferenciji Stulikon u Beogradu, održanoj u maju 2019. godine. 
jeziku i u njemu dešifruju (Драгићевић 2007: 90). U Rečniku srpskog jezika Matice srpske (2007) pod odrednicom istina nalazi se sledeća definicija:

istina ž 1. ono što odgovara stvarnosti, činjenicama: $\sim$ o borbama, $\sim \mathrm{o}$ događaju. 2. činjenica u koju se kao dokazanu može verovati: naučna . 3. visoki moralni princip, pravda. 4. istinitost, verodostojnost.

Kao što se može primetiti, rečnička definicija precizira uži sadržaj pojma i izvodi se na osnovu strogo postavljenih pravila kao što su akuratnost, neslikovitost itd. S obzirom na to da definicija treba nedvosmisleno da određuje pojam, problem se ne javlja kod definisanja leksikalizovanih čulno saznatljivih pojmova, nego kod onih apstraktnih koji nisu iskustveno dostupni. Takvi pojmovi u mišljenju i jeziku podležu konkretizaciji i svođenju na poznato iskustvo. U vezi s tim, jedno od pitanja koje se može postaviti jeste to kako se o određenom apstraktnom pojmu govori i šta se na osnovu toga može zaključiti kada je u pitanju čovekovo poimanje i organizovanje stvarnosti koje se očitava upravo u jeziku. Odgovor može da pruži konceptualna analiza. U pitanju je metoda namenjena ispitivanju leksikalizovanih apstraktnih pojmova, koja je u lingvistici značajna jer se pomoću nje može doći do opisnih definicija koje doprinose boljem razumevanju čulno nesaznatljivog sveta koji okružuje čoveka. Iznikla je iz kognitivistike, složene discipline koja za predmet svog proučavanja uzima ljudski um i kognitivne fenomene kao što su percepcija, mišljenje, razumevanje jezika i sl. (Klikovac 2004: 7-10). U okviru kognitivne lingvistike značenje se izjednačava s konceptualizacijom.

Treba naglasiti da se u lingvističkoj literaturi pod konceptualizacijom podrazumeva obrazovanje pojmova na osnovu fizičkog, čulnog, emocionalnog, intelektualnog iskustva sa svetom koji ga okružuje. Apstraktni pojmovi se konceptualizuju pomoću pojmovne metafore koja se zasniva na razumevanju čulno nesaznatljivog, apstraktnog pojma (ciljnog domena) pomoću čulno saznatljivog, konkretnog pojma (izvornog domena). Stoga, kao teorijski okvir ovog istraživanja poslužila je teorija pojmovnih metafora Lejkofa i Džonsona koja ističe povezanost jezika, mišljenja i fizičkog iskustva. ${ }^{2}$ Izvorni domeni povezani su skalom

${ }^{2}$ Lejkof i Džonson razlikuju tri vrste pojmovne metafore: strukturne, orijentacione $\mathrm{i}$ ontološke (Lejkof - Džonson 1980). Pojmovne metafore pomoću kojih se govori o apstraktnom pojmu istina najvećim delom su ontološke i zasnivaju na razumevanju 
apstraktnosti. Izvorni domen može biti predmet, živo biće-biljka, životinja, čovek; materija, svetlost, prostor itd. O neodvojivosti kategorija, pojmova i iskustva, Lejkof i Džonson (1999 - 2014: 244) u članku Utelovljeni um navode sledeće:

„Živi sistemi moraju da kategorizuju. Pošto smo neuronska bića, naše kategorije se obrazuju našom utelovljenošću. To znači da su kategorije koje obrazujemo deo našeg iskustva! One su strukture koje izdvajaju aspekte našeg iskustva u međusobno različite vrste. Kategorizacija, dakle, nije čisto intelektualna stvar, koja nastaje posle iskustva. Pre će biti da se iskustvo upravo sastoji od obrazovanja i upotreba kategorija."

Metodologija istraživanja svodi se na ekscerpciju građe iz korpusa (Korpus savremenog srpskog jezika) - ekscerpciju rečenica u kojima je leksema koja označava apstraktni pojam kontekstualizovana - i utvrđivanje pojmovnih metafora kao mehanizama mišljenja. U pitanju je korpus koji čini kolekcija tekstova u digitalnom obliku, koji pripadaju različitim funkcionalnim stilovima. Stoga se prilikom analize empirijskog materijala neće navoditi konkretni izvori pored izdvojenih rečenica $\mathrm{u}$ kojima je leksema koja označava apstraktni pojam kontekstualizovana, ali svakako će se na njih obratiti posebna pažnja prilikom izvođenja procentualne analize pripadnosti date lekseme određenom funkcionalnom stilu. Treba naglasiti da izdvojene rečenice, u kojima je leksema koja označava apstraktni pojam kontekstualizovana, nisu uvek date u celosti; istrgnute su iz konteksta, no dovoljne da se razabere značenje date lekseme. Analiza se sprovodi na minimalnim kontekstualnim spojevima apstraktne imenice istina s predikatima fizičke radnje, deskriptivnim pridevima i konkretnim imenicama. Ti spojevi javljaju se kao rezultat kolektivnog nadsaznanja, a saznanje nosilaca srpskog jezika prima ih kao mitologeme sa određenim smislom (Чернейко prema Ристић 1999: 156).

Istraživanje je sprovedeno s ciljem da se izdvoje izvorni domeni u kojima se konceptualizuje istina kao apstraktni pojam, ali i da se ukaže na elemente u

apstraktnih pojmova preko entiteta, materije, pojava (npr. servirati istinu, seme istine, žaoka istine, sahraniti istinu, kap istine, ozaren istinom) i orijentacione koje se zasnivaju na razumevanju apstraktnih pojmova preko orijentisanja u prostoru (npr. živeti $u$ istini). S druge strane, strukturne metafore zasnivaju se na metaforičkom strukturiranju jednog pojma pomoću drugog (npr. ŽIVOT JE PUTOVANJE (On nema pravac u životu)). 
konceptualizaciji njihovog značenja koji otkrivaju osobenosti duha i kulture nosilaca srpskog jezika (Ристић 1999: 158). Cilj istraživanja je i izvođenje procentualne analize zastupljenosti određenih pojmovnih metafora prema broju primera te izvođenje zaključka kako se apstraktni pojam najčešće konceptualizuje. Takođe, skreće se pažnja u kojem funkcionalnom stilu je data leksema najfrekventnija.

\section{Analiza empirijskog materijala}

U Korpusu savremenog srpskog jezika nalazi se ukupno 31.366 primera s oblikom istin- kao korenskom morfemom, što je bio i upit za ovo istraživanje.

Analiza korpusa pokazala je sledeće: leksema istina najfrekventnija je u književnoumetničkom (162) i publicističkom (105) funkcionalnom stilu. Leksema je manje frekventna u naučno-popularnom (30) i naučnom funkcionalnom stilu (3). Leksema istina ne pojavljuje se $\mathrm{u}$ administrativnom stilu. Treba, međutim, naglasiti da bi se daljom ekscerpcijom građe ovi podaci menjali, ali ne drastično jer je za svrhe ovog istraživanja sagledano preko 12.000 primera što grubo odgovara trećini raspoloživog korpusa.

Nakon analize građe, izveden je zaključak da se apstraktni pojam leksikalizovan kao istina na prvom mestu konceptualizuje kao osoba (139), zatim kao predmet (136), materija (10), svetlost (5), biljka (5), prostor (3) te životinja (2).

U radu se neće navoditi svih trista primera. Navodiće se primeri koji najbolje ilustruju svaki izvorni domen u okviru kojeg se konceptualizuje apstraktni pojam i to tako što će se krenuti od manje frekventnih izvornih domena.

ISTINA JE ŽIVOTINJA:

a) ISTINA JE OPASAN INSEKT: Istina može da ubode. Istina može emocionalno da povredi čoveka kao što žaoka može fizički da ga povredi: žaoka istine (Lengdon oseti žaoku istine u ovoj izjavi.). Istina se preko osećaja bola koji može da nanese negativno konotira.

b) ISTINA JE LARVA: Istina je učaurena, ne može se lako promeniti, po prirodi je postojana: učaurena istina (Strategija polemičara bila je insistiranje da je 
suštinska istina porekla pravoverja bila učaurena u pravilu vere ...). Istina se preko osobine postojanosti pozitivno konotira.

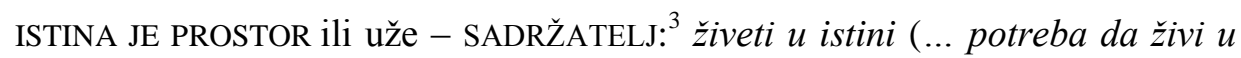
istini ...), preći granice istine (... nadam se da nećete otkriti da je prešao granice istine višse no što mu se može oprostiti ...), ići rubom istine (Nastavio je da priča, nastojeći da ostavi utisak kako je potpuno iskren, a ne da ide samim rubom istine.). Istina se poima kao duhovni prostor u kojem čovek pun vrline treba da živi. Prelazak njenih granica predstavlja duhovni pad. Istina se preko ove pojmovne metafore pozitivno konotira.

ISTINA JE BILJKA: seme istine (... čupao je iz svesti seme one istine koju je u njemu posejao Garanža.), negovati istinu (Zadatak ovog društva je negovanje istine o Titu i njegovim saborcima ...), gajiti istinu (... kad se jedna istina, gajena in vitro, u bujonu vlastitog mozga ...), ukorenjena istina (... ta je istina tako duboko ukorenjena u svesti susednih porodica ...), zrno istine (Iskusni i oštroumni kakvi su, Travničani su iz tih laži mogli često da izvuku zrno istine, za koje ni sam varalica nije znao da se nalazi među njegovim lažima.). Istina je vrednost zametnuta u čoveku poput semena u zemlji, mora se negovati, gajiti kako bi se razvila i ukorenila. Istina se preko ove pojmovne metafore pozitivno konotira.

ISTINA JE SVETLOST: ozaren istinom (Ozaren sam jednom novom istinom ...), istina zasija ( $\mathrm{Pa}$ da istina što pre zasija, eto zašto!), istina sine (... ovaj beli srebrnjak biće za vas sjajno ogledalo u kome će da sine čista istina.), istina blesne (Naposletku blesnu istina.), istina dopire (Kako da istina dopre do njega?). Istina je čoveku kao duhovnom biću neophodna, prijatna poput svetlosti, toplote. Čovek ne voli tamu, užasava je se. Istina se preko svetlosti pozitivno konotira.

\footnotetext{
${ }^{3}$ Po Lejkofu i Džonsonu, metafore sadržateljskog tipa počivaju na analogiji s ljudskim bićima koja imaju svoje granice i orijentaciju unutar-izvan pa se ova orijentacija preslikiva na nefizičke objekte (kakva je, npr. istina) transformišući ih u fizičke objekte s jasnim granicama.
} 
ISTINA JE TEČNOST/TEKUĆINA: Uočena je konceptualizacija apstraktnog pojma kao tečnosti koju čovek unosi u organizam i kao tečnosti koju iz njega izbacuje. Kod ove pojmovne metafore mogu se izdvojiti četiri podgrupe:

a) ISTINA JE VODA: Istina je neophodna čoveku kao duhovnom biću isto toliko koliko mu je neophodna voda kao fizičkom biću: napajati se istinom (... smatrajuci da razborita nastrojenost ne treba da se njome hrani, već valja da se napaja samo istinom ...), žedan istine (Opredelio sam se za žeđ za istinom koja je pokretala Bernara Gija.), vapiti za istinom (A biće mu grob u grobu koji vapi za istinom ...).

b) ISTINA JE MLEKO: zadojiti istinom (... on je zadojen ljubavlju, istinom, postojanjem, otadžbinom, svojim krstom.). Istina omogućava duhovni razvoj čoveku kao što mu hrana/mleko omogućava fizički razvoj. Istina se preko osobine neophodnosti za čoveka pozitivno konotira. Kod obe pojmovne metafore uočavaju se pozitivne komponente u konceptualizaciji značenja datog pojma.

c) ISTINA JE GORKO PIĆE: gorka istina (Tek tada sam se opustila, prihvatila $i$ primila gorku istinu.). Istina se preko svojstva gorčine negativno konotira.

d) ISTINA JE PLJUVAČKA, POVRAĆKA: Istina je tečnost koju čovek treba da izbaci iz organizma: pljuvati istinu (Pljuvali smo istinu Srbiji u lice.), bljuvati istinu (Žare ceni hip-hop bendove, koji bljuju istinu u lice.). Istina se preko ove pojmovne metafore negativno konotira $\mathrm{i}$ to $\mathrm{u}$ odnosu na recipijenta kojem je upućen ovaj negativni sadržaj.

Grafikon 1: Istina je tekućina koju čovek konzumira i/ili izbacuje

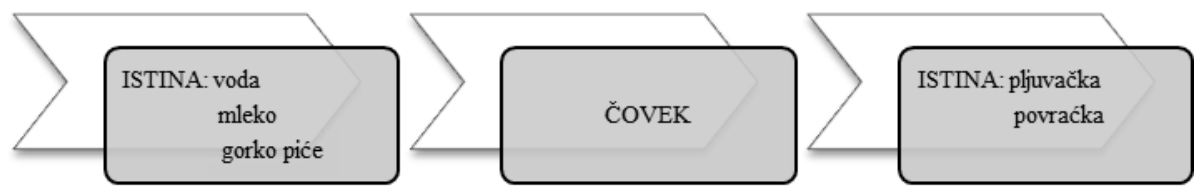

ISTINA JE PREDMET: Analiza korpusa pokazuje da se istina veoma često konceptualizuju kao predmet, koji treba šire shvatati, pa se tu može izdvojiti nekoliko podgrupa, kao što su hrana s primerima servirati istinu, zgotovljena 
istina; novac s primerom dugovati istinu (Sada svetu dugujete istinu.); roba $\mathrm{s}$ primerima istina košta, jeftina istina, prokrijumčariti istinu, zameniti istinu za nešto, fabrikovati istinu, držati monopol na istinu, proizvoditi istinu, plasirati istinu; zatim tkanina jer primeri pokazuju da se istina može prekrajati (... istina koja se ne može menjati i prekrajati ni na orvelovski, ali ni na bilo koji drugi način.), izvrtati (... bilo je nemoguće ne osetiti da je posredi grubo izvrtanje istine s jedne ili druge strane ...); građevina što se može zaključiti na osnovu primera sazdana istina (... do Jona Gabrijela Borkmana $i$ do istine sazdane po njegovoj meri ...); te teret, što pokazuje primer istina se sručuje na nekoga (Tibing oseti kako se istina hladno i bolno sručuje na njega.). Konceptualizacija istine kao tereta ukazuje na to da je trpljenje neke duhovne neprijatnosti njena bitna semantička komponenta (Драгићевић 2007: 101).

S druge strane, istina se konceptualizuje kao dragocen predmet koji treba čuvati, paziti da se ne izgubi ili kao predmet koji treba sakriti od ljudi: (sa)čuvati istinu, izgubiti istinu, zagubiti istinu; sakriti istinu, zataškavati istinu, zabašuriti istinu, prikriti istinu, zastirati istinu, staviti istinu na dno bunara, smeštati istinu na određeno mesto, zaklanjati istinu, zamagliti istinu, zapečatiti istinu. Kod ovih pojmovnih metafora uočavaju se kako pozitivne tako i negativne komponente $\mathrm{u}$ konceptualizaciji značenja datog pojma. S jedne strane u pitanju je dragocen predmet koji iziskuje pažnju onoga ko ga čuva, s druge strane predmet koji treba sakriti od svih zbog mogućih neprijatnosti i nevolja koje može da prouzrokuje onome ko naiđe na njega ili ga pronađe ili onome ko ga poseduje.

Istina se konceptualizuje kao kakav udaljen, dragocen predmet za kojim se traga i koji treba izneti na svetlost dana. Stoga se kod ovih pojmovnih metafora uočavaju pozitivne komponente u konceptualizaciji značenja datog pojma: tragati za istinom; tražitilpronaći, otkriti, izvući, iskopati, iznositi, istrgnuti, raskrivati, pokazati, obelodaniti, izložiti, iščupati, istrljati iz nečega, otkopati, osvetliti istinu, nedosegnuta istina.

Istina se konceptualizuje i kao predmet koji se može modifikovati: zacementirati istinu, iskriviti istinu, razbiti istinu, oblikovati istinu, spaliti istinu, očistiti istinu, zamaskirati istinu, kriviti istinu (u značenju 'iskriviti'), natezati istinu, deformisati istinu, te kao predmet kojim se rukuje: baratati istinom, vršiti eksperimente s istinom, raspolagati istinom, operisati s istinom. Kod ovih pojmovnih metafora uočavaju se negativne komponente u konceptualizaciji datog pojma jer je u pitanju predmet koji podleže modifikaciji u korist onoga ko ga 
poseduje ili onoga ko ga prima. Slične komponente uočavaju se i kod konceptualizacije datog pojma kao tkanine, građevine.

ISTINA JE OSOBA: Kao što je na početku rečeno, istina se najčešće konceptualizuje kao osoba. Najveći broj primera pokazuje da je to osoba koju pokoravamo, osoba kojoj se ne pokoravamo i osoba kojoj se pokoravamo. To se može zaključiti na osnovu primera udaviti istinu (Udavimo istinu.), suočiti se sa istinom (Kada se konačno suočimo sa istinom samom, nemoćni smo.), te služiti istini (Zaboga, devojko, zar ne možeš da služiš istini malo umerenije?).

Ova klasifikacija izvedena je na osnovu rada ruskog lingviste L. O. Černjejka o personifikaciji sudbine u ruskom jeziku predstavljenoj tzv. geštalt-metodom (Чернейко prema Драгићевић 2007: 94). Na osnovu konceptualizacije istine kao nadređene osobe/vladarke (pokoriti se istini, istina osvaja, istina nadvladava, istina se može ustoličiti, istina može biti neprikosnovena, istina zahteva, istina oslobađa, istina pobeđuje, istina se nameće, istina govori, istina uzima pravo, za istinom se ide) te kao neprijatelja/protivnika/suparnika (boriti se protiv istine, pogledati istini u lice, pogledati istini u oči, suprotstavljati se istini, sučeljavati se $s$ istinom, boriti se $s$ istinom, obračunati se $s$ istinom), može se reći da je agentivnost njena bitna odlika. S druge strane, konceptualizacija istine kao potčinjene osobe, mučenice, žrtve (istinom se vlada, istina služi, vređati istinu, povrediti istinu, izobličiti lice istini, ubiti istinu, udaviti istinu, izmanipulisati istinu, isterati istinu, istina izdržava, istina se guši, izneveriti istinu, smejati se istini, izigrati istinu, pljunuti istini $u$ oči, preoteti šansu istini) upućuje na pasivnost kao njenu izrazitu odliku.

Uočena je konceptualizacija istine kao osobe vredne poštovanja, uvažavanja, zaštite: poštovati istinu, ceniti istinu, voleti istinu, biti privržen istini, istina može biti draga nekome, nekome je stalo do istine, postarati se za istinu, imati obzira prema istini, uvažavati istinu, štititi istinu, ginuti za istinu. Istina se preko ove pojmovne metafore pozitivno konotira.

S druge strane, istina se konceptualizuje kao osoba koja smeta, koja je predmet mržnje (izbegavati istinu, podnositi istinu, istina može da smeta, odbaciti istinu, mrzeti istinu, biti gord na istinu).

U skladu s prethodno navedenim, istina se konceptualizuje i kao osoba koja donosi bol (istina utuče, istina okreće leđa, istina razočara, plašiti se istine). Istina se preko ovih pojmovnih metafora negativno konotira zbog neprijatnosti, nevolja ili bola koji donosi onome ko stupi u kontakt s njom. 
Takođe, govornici koji potiču sa srpskog kulturnog područja poimaju istinu te o njoj i govore kao o osobi s određenim osobinama, pozitivnim (5) i negativnim (11), što se može zaključiti na osnovu sledećih primera: nepodnošljiva, surova, grozna, svirepa, opasna, nesnosna, iskvarena, neuverljiva, autistična, tužna, pokolebana; tajanstvena, nedohvatna, neumoljiva, objektivna, nepogrešiva istina.

\subsection{Kulturološki aspekt pojmovne metafore na primeru koncepta istina}

Po ugledu na rad posvećen konceptualizaciji tuge (Драгићевић 2007: 100), u kojem se iznose dijahronijski podaci zarad potvrđivanja pojmovnih metafora do kojih se došlo sinhronijskom analizom, u ovom radu na dva primera ilustrovaće se način na koji je to učinjeno. Za potrebe ovog rada neće se zalaziti u detaljnu etimološku analizu niti će se posebna pažnja posvećivati razrađivanju ovog postupka s obzirom na to da on i nije predmet ovog istraživanja.

Kada je u pitanju etimologija, na osnovu koje se takođe može sagledati prvobitno razumevanje pojma istina, izdvajamo primer engleskog i španskog jezika. Engleska imenica truth (istina) potiče od praindoevropskog *deru- (čvrst, postojan). U etimologiji ove imenice nalaze se metafore sazdati istinu/sazdana istina, učaurena istina, ukorenjena istina itd. Španska imenica cierto (istina) potiče od latinske reči certus (postojan, rešen/odlučan). U etimologiji ove imenice nalaze se metafore ustoličena istina, neumoljiva istina itd. Na osnovu ovoga može se zaključiti da etimologija leksema koje označavaju istinu u ovim jezicima ilustruje konceptualizaciju istine sa sinhronijskog stanovišta.

Isto tako, važna su istraživanja koja ispituju stepen univerzalnosti pojmovnih metafora, u kojima se posmatra i udeo kulturoloških elemenata u procesu konceptualizacije apstraktnih pojmova i pojava. Jedan od istaknutih semantičara koji se bavi ovom problematikom jeste Zoltan Kevečeš, a ovom prilikom iznosi se samo segment važnog istraživanja (Kövecses 2011), u kojem se ispitivani fenomen posmatra u kontekstu usvajanja stranog jezika.

Može se izneti pretpostavka da se pomoću konceptualne analize paralelnim izučavanjem apstraktnih pojmova leksikalizovanih na drugačije načine u različitim jezicima može pronići u kulturološke razlike kada je u pitanju njihovo poimanje, pogotovo onih iz etičkog domena u koji spada i istina. Pojmovne metafore pomoću kojih se govori o apstraktnim pojmovima jesu gotovo univerzalne, ali mogu se pojaviti razlike koje proističu iz raznolikog kulturalnog i fizičkog okruženja (Kövecses prema Драгићевић 2007: 91). 
Dragoceno bi bilo izvršiti konceptualnu analizu leksikalizovanih apstraktnih pojmova koji su kulturološki markirani i za koje u drugim jezicima ne postoje adekvatni ekvivalenti (npr. merak, sevdah itd.). Kada je u pitanju usvajanje stranih jezika, opisne definicije leksikalizovanih apstraktnih pojmova izvedene na osnovu rezultata do kojih se došlo pomoću konceptualne analize doprinele bi hvatanju nevidljivog sloja prilikom usvajanja značenja određenih leksema, koji je deo jezičkog osećanja izvornih govornika. Krajnji cilj ovakvog poduhvata mogla bi biti izrada rečnika kulturološki markiranih apstraktnih pojmova. Sličan poduhvat izveden je 1996. godine kada je grupa autora na čelu sa E. S. Kubrjakovom objavila Kratak rečnik kognitivnih termina (Драгићевић 2007: 93).

\section{Zaključak}

Nakon analize građe, izveden je zaključak da se apstraktni pojam istina pozitivno konotira u svesti izvornih govornika - kao duhovni prostor, larva koju odlikuje postojanost, biljka, svetlost, voda, mleko; kao dragoceni predmet koji treba čuvati, paziti da se ne izgubi, kao kakav udaljen, dragoceni entitet za kojim se traga i koji treba izneti na svetlost dana; kao osoba vredna poštovanja, uvažavanja i zaštite, te kao osoba s pozitivnim osobinama.

$\mathrm{S}$ druge strane, veliki broj primera pokazuje da se istina konotira i negativno u svesti izvornih govornika - kao opasan insekt koji može da nanese bol, kao gorko piće, kao pljuvačka, povraćka, teret; kao predmet koji treba dobro sakriti od svih ili modifikovati zbog mogućih neprijatnosti i nevolja koje može da prouzrokuje onome ko naiđe na njega ili ga pronađe, onome kome je upućen ili onome ko ga poseduje; kao osoba sa nepoželjnim osobinama, kao osoba koja donosi neprijatnosti, nevolje ili bol onome ko stupi u kontakt sa njom.

Izvedeni zaključak potkrepljuje tvrdnju da pojmovne metafore pomoću kojih se govori o određenom apstraktnom pojmu nisu logički uporedive, nego koherentne svaka pojmovna metafora osvetljava jedan aspekt pojma i nijedna nije dovoljna za njegovo potpuno razumevanje (Klikovac 2004: 87).

Ukoliko bi se dala opisna definicija apstraktnog pojma leksikalizovanog kao istina, to bi se učinilo na sledeći način:

Istina je prostor u kojem čovek može da bitiše, odnosno da se u njemu kreće (živeti u istini, preći granice istine); svetlost (ozaren istinom); materija (kap istine, istina procuri); predmet koji čovek koristi u 
svakodnevnom životu (dugovati istinu); biljka koja raste i nastanjuje svet u kojem čovek živi (seme istine); životinja (žaoka istine); čovek od krvi i mesa (gola, naga, zaodenuta istina, frizirati istinu, sahraniti istinu), osoba sa kojom može da se stupa u najrazličitije odnose (ljutiti se na istinu, pomiriti se sa istinom).

Grafički bi se ovo moglo prikazati na sledeći način:

Grafikon 2: Primarne metafore pojma istina

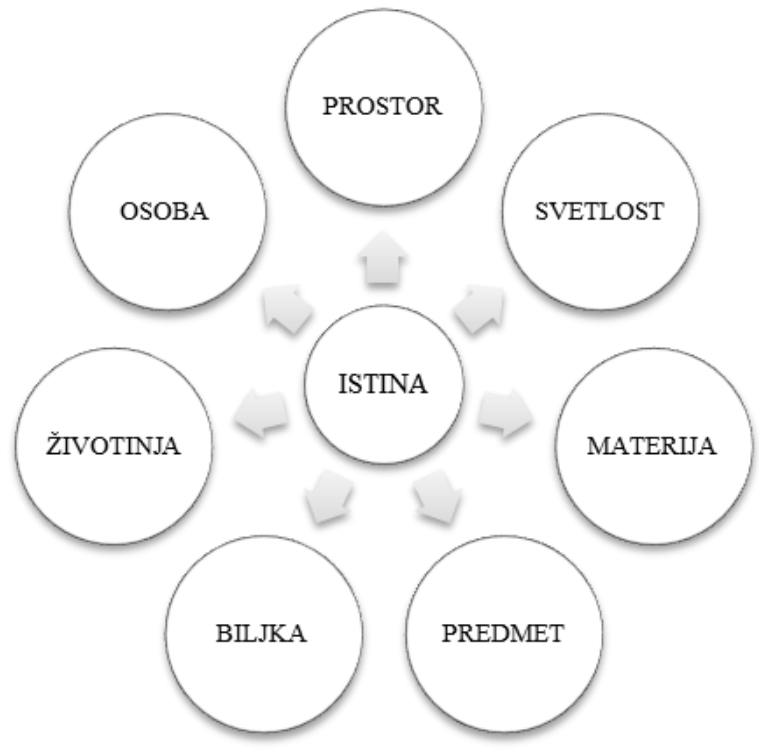

I Z V O R I

Elektronski korpus srpskog jezika <http://korpus.matf.bg.ac.rs/prezentacija/korpus.html> Online etymology dictionary <https://www.etymonline.com/>

Online etymological dictionary of Spanish 〈https://www.spanishetym.com/>

RSJ: Rečnik srpskog jezika. Novi Sad: Matica srpska, 2007.

\section{LITER A T UR A}

Klikovac, Duška (2004). Metafore u mišljenju i jeziku. Beograd: Biblioteka XX vek.

Kövecses, Zoltán (2011). Idioms, Metaphors, and Motivation in Foreign Language Teaching. Jezik u upotrebi / Language in Use. Zbornik u čast Ranku Bugarskom (ur. Vera Vasić). Filozofski fakultet: Novi Sad. 253-271. 
Lejkof, Džordž, Mark Džonson (1999/2014). Utelovljeni um. Jezik i saznanje. Hrestomatija iz kognitivne lingvistike (ur. K. Rasulić, D. Klikovac). Beograd: Filološki fakultet. 241-273.

Драгићевић, Рајна (2007). Лексикологија српског језика. Београд: Завод за уџбенике. Ристић, Стана, Милана Радић-Дугоњић (1999). Концептуализација неких речи из сфере духовности носилаца српског језика. Реч. Смисао. Сазнање. Београд: Филолошки факултет у Београду. 155-169.

Jovana Jovanović

\section{METAPHORS OF TRUTH IN SERBIAN LANGUAGE}

\section{SUMMARY}

This paper discusses the conceptualization of the abstract notion lexicalized as truth in order to establish the conceptual metaphors as mechanisms of comprehension. The research rests on the postulates of the conceptual method, one of the crucial tools for examining meanings in cognitive linguistics. The research is being conducted on the Corpus of contemporary Serbian (SrpKor), from which three hundred different examples of a contextualized lexeme will be extracted, and the functional affiliation of the selected examples will be observed. A statistical analysis will be conducted, which involves insight into the frequency of the conceptual metaphors' source domains. Finally, the elements in the conceptualization of this abstract notion which reveal cultural peculiarities of native speakers will be analyzed.

KEYWORDS: conceptualization, conceptual metaphor, source and target domain, istina (truth).

Jovana Jovanović

Odsek za srpski jezik i lingvistiku Filozofski fakultet, Univerzitet u Novom Sadu

Srbija jovanajovanovic3150@gmail.com 